\title{
Towards Safe Streets: The relationships between Physical Attributes of Streets and Perceptions of Pedestrian Safety in Kandy, Sri Lanka
}

\author{
Akila Ranasinghe, Narmada Wijekoon, Janaka Wijesundara \\ Centre for Cities, University of Moratuwa, Sri Lanka. \\ Corresponding Author Email: akilaband@yahoo.com
}

\begin{abstract}
Each year, over 1,000 pedestrians on Sri Lankan streets and more than 270,000 on world's streets lose their lives and some are left with permanent disabilities. Compared to other road traffic fatalities and injuries, pedestrian accidents are seen as significantly high. Therefore, the pedestrian safety is a major issue on streets, and it has to be addressed in a serious manner. Safety being a basic need of every human being, it is essential that the built environment facilitates the safety needs. In here, Architecture and Urban Design would play a vital role in ensuring both physical as well as psychological safety of users. Cities, being the containers of large populations, naturally involve with the gathering of large numbers of people on streets, hence it is crucial to guarantee the safety of the pedestrians in cities.
\end{abstract}

This paper explores the links between perception of safety and physical attributes of pedestrian spaces. It identifies the legitimate physical attribute combinations that help to ensure the safety within pedestrian space with the aim of mitigating and preventing the pedestrian accidents. This reviews the significant theories related to the field of architecture and urban design and the key attributes such as built form, planning and layout, ambience and functions used to facilitate the safety. The study engages with examining of variables of perceived safety and physical attributes of pedestrian areas, by appropriately using qualitative and quantitative research methods and, studying the city of Kandy as a case.

The study concludes that the perception of safety of a pedestrian depends not merely on the physical aspects of pedestrian space, but also on the positive combinations of physical and psychological attributes.

Keywords: Perception of safety, Pedestrian space, Physical attributes, City of Kandy, Sri Lanka 


\section{Introduction}

As a world-wide trend, cities are being developed in order to facilitate the people who live, work and entertain in the city premises. In cities, the pedestrians are one most important and key component through which the city image and its character is generated based on the type of activities that the people engaged with, and the places where they hang around.

In addition, the place where pedestrian activities happen can be identified and simply defined as 'pedestrian space'. Accordingly, pedestrians are the most vital component of an active city where agglomeration of diverse and dynamic activities take place while serving extensive users and being the engine of the city's activeness. The key forms of pedestrian space where people walk, sit, shop, play or interact are identified as sidewalks, alleys, lanes.

Unfortunately, the pedestrians are rarely the subject of careful planning and design of streets and usually it regulates itself or is an effect of building an extensive system of road network.

In Sri Lanka, most populated cities like Colombo, Kandy and Galle and core areas of other towns are formed mostly with busy commercial and transportation oriented activities. That is because, aforementioned cities and majority of the towns have been planned and arranged where all the needy activities are met and concentrated into one central point rather decentralizing. Accordingly, each space in the city has a particular hierarchical value as well as magnitude of usage. Compared to American or European contexts, most Asian and Sri Lankan cities have less attention and concern on the pedestrian spaces causing unsafe, unsecured and uncomfortable conditions. As streets cover massive part of any city, sidewalks as the pedestrian space are considered to be well designed and constructed according to appropriate standard/s and maintenance mechanisms. Condition of the pedestrian space consists of many physical attributes that impact directly and indirectly on safety of pedestrians.

In known terms, safety means the feeling of secure, being without physical and psychological harm. "Feeling safe is to feel protected. It is a feeling of well-being which can envelop a family, a community, a neighborhood and a city. Its composition is hard to decipher, but it is an all -encompassing feeling of calm which is often as invisible as clean unpolluted air and, inversely, when fear and anxiety take its place, that feeling is as palpable as though it was a physical reality." (Patel, 1998)

Lack of safety on streets can be casual due to the absence of physical protection such as physical harassments, threats from automobile accidents, injuries by uneven sidewalks, edges etc. as well as absence of mental protection such as unpleasantness, suspicion or distrust to walk through. "Feeling safe is crucial if we hope to have people embrace the city space. In general life and people themselves make the city more inviting and safe in terms of both experienced and perceived security" (Gehl, 2010)

Accordingly, this paper focuses on the physical attributes of streets which impact on the perception of safety while establishing a research position, highlighting the research gap in combinations of independent physical attributes to ensure the safety within pedestrian spaces. Along with that, this paper aims to; 
(a) Investigate the physical factors of streets that people prefer as safe focusing on its built form, planning, ambience and the functions which disclose the most legitimate attribute combinations in creating safer pedestrian spaces to overcome with the solutions for negative physical attributes for a better city life,

(b) Identify the potentials and design strategies to improve perception of safety within the streets to rebuild the strong discussion between user and space,

(c) Reveals the relationship between perception of safety and physical attributes of pedestrian spaces,

(d) Studying a case where the sense of unsafe is present and understand about creating safer pedestrian spaces in urban design to gain its maximum utilization as well as a crime friendly situation reducing the crime chain.

\section{Literature Review}

Respectively, in the attempt of orienting cities as pedestrian friendly cities rather than automobile oriented cities, it's important to verify and validate the contribution of physical attributes of pedestrian spaces towards perception of safety.
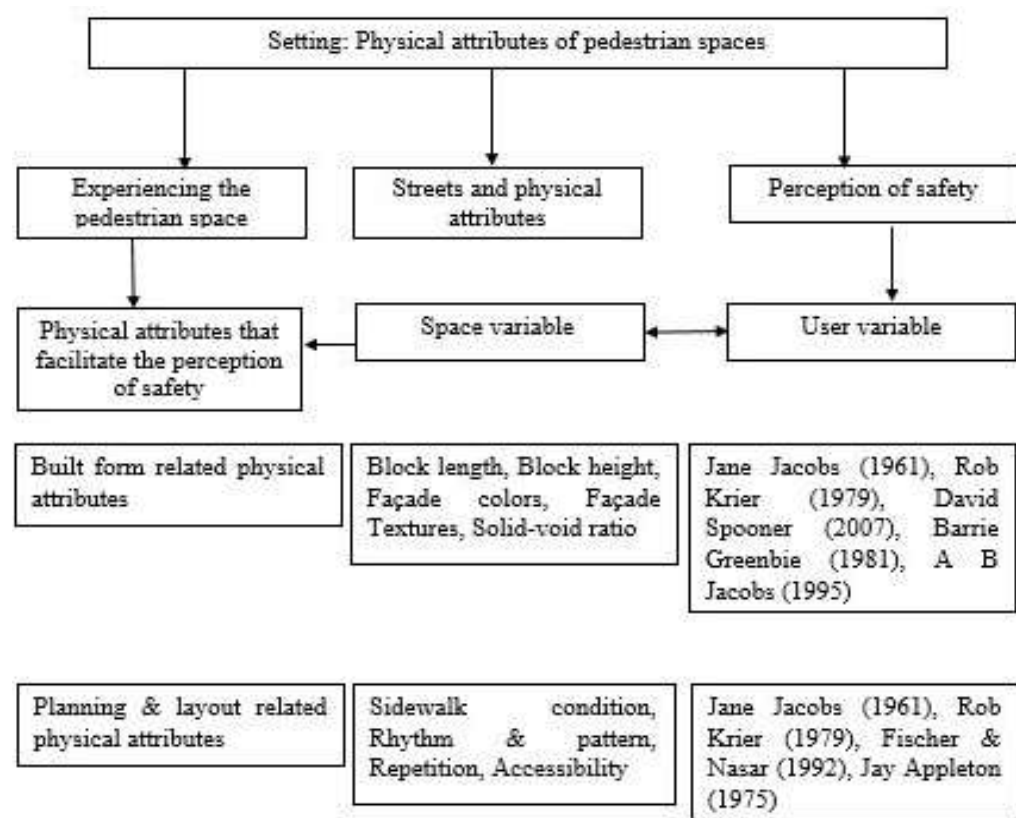

\begin{tabular}{|l|l|}
\hline $\begin{array}{l}\text { Ambience related physical } \\
\text { attributes }\end{array}$ & $\begin{array}{l}\text { Visibility, lighting levels, } \\
\text { Shadings, Historic presence }\end{array}$ \\
\hline
\end{tabular}

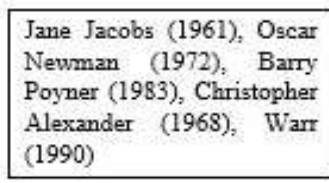

\begin{tabular}{|l|l|}
\hline $\begin{array}{l}\text { Functional related physical } \\
\text { attributes }\end{array}$ & $\begin{array}{l}\text { Formal/Informal activities, } \\
\text { Special activities }\end{array}$ \\
\hline
\end{tabular}

Jane Jacobs (1961), Vikas
Mehta (2010), Goffman
(1971), Warr (1990)

Fig. 1: Theoretical Backbone of the study 
Source: Author

- As above, the theoretical framework which is developed through the literature review is used to study the pedestrian space and safety, and fifteen physical attributes are selected under four key categories namely; built form, planning \& layout, ambience and functions.

- Some attributes like Block height, façade colors, façade textures, solid-void ratio, rhythm \& pattern, repetition and historic presence are not addressed towards the perceived safety by some theoreticians. Some scholars discuss these attributes in city planning theories. However, the research studies on the contribution of these physical attributes towards the perception of safety are somewhat scarce.

\section{Methodology}

\section{Site selection criteria- Kandy}

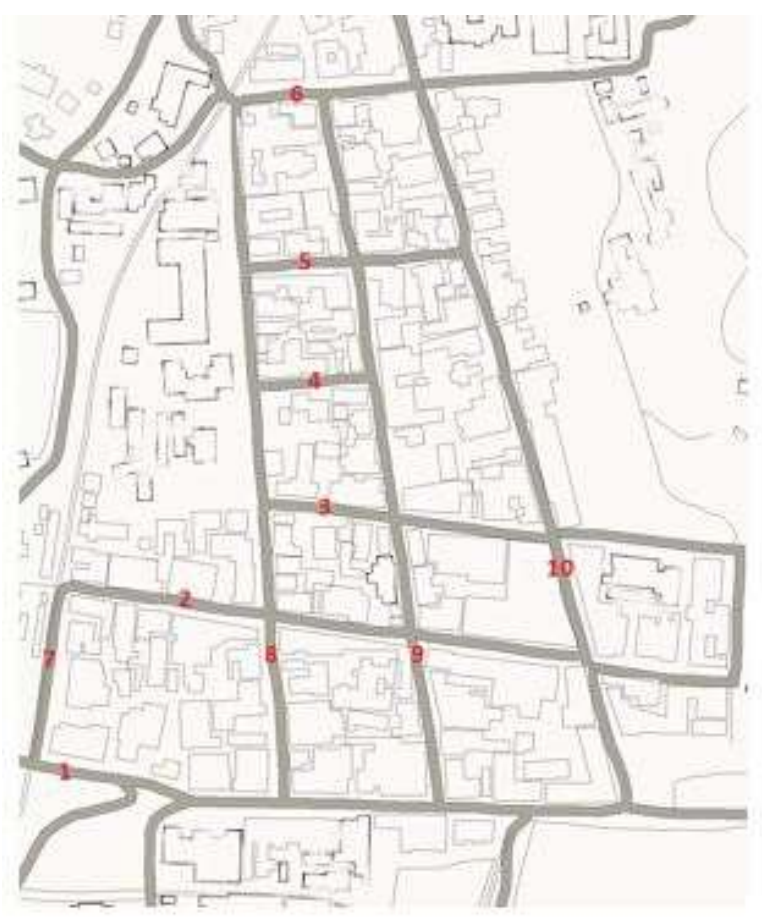

1. Dalanda street

2. Colombo street

3. King street

4. Prince street

5. Cross street

6. Hill street

7. Wadugodapitiya street

8. Yatinuwara street

9. Kotugodalla street

10. D S Senanayake street

Fig. 2: Kandy Grid City

Source: Author

Kandy is an ancient heritage city which considers as the second major city of Sri Lanka. Many people visit the city due to its Archeological/heritage value, significant climatic conditions and the consistency of sacred places and activities. Also, Kandy city is consisted with multi religious and ethnic backgrounds and vast cultural diversity.

Asserting the suitability of Kandy city as a case to this research, there are ten streets within the city itself which are commercial oriented and have diverse pedestrian flow and density, complex vehicle movement patterns, identical building/façade and space character, inherent commerce based functions and significant religious as well as cultural composition under key planning and building regulations. 


\section{Flow of the Study}

Stage 1 - As the key objective, the legitimate combinations of physical attributes that facilitate the perception of safety will be understood. In the first stage, people have been asked to indicate their opinion on the safety (as safe, as unsafe, neutral) in selected ten streets.

Randomly selected participants (six from each street) of above the age of fifteen from the case location were given questionnaires. One sample from each street is a tourist to avoid familiarity and to obtain more qualitative data.

Stage 2 - In the stage two, shop owner from each street is interviewed to verify and validate previously collected data. Purpose of these questionnaires and semi - structured interviews are to reveal the safety levels of each street to conduct a comparative study. All the streets were studied to review both positive and negative physical attributes using participants and personal observations, photographic survey, counting survey and interviews to pedestrians, permanent shop owners and temporary business people.

While conducting the research, following limitations is taken in to consideration.

a) Perception of safety is a feeling that depend on many aspects like age, gender, race, culture etc. (Mehta, 2013) Besides the user experience in perception of safety has a diversity from a person to another (Tuan, 1977) . But this study is limited to the physical attributes of pedestrian space as the dependent factor of perception of safety.

b) The questionnaires are limited to the different segments of commercial oriented streets in Kandy grid city.

c) People believe that the streets which are close to the sacred area as safe spots.

d) Any of ten streets were not arranged according to the present street design guidelines due to an ancient city, therefore comparative study has to be carried out.

e) Samples were picked to cover the all segments of streets but tourists were considered only the immediate atmosphere of the particular streets when answering the questions.

\section{Analysis}

1. Following summery charts were used per each street to present the data extracted from pedestrians.

\begin{tabular}{|c|c|c|c|}
\hline \multirow{2}{*}{ Sumple Xe. } & \multicolumn{3}{|c|}{ Luer Respentin } \\
\hline & satt & Nrensol & Cont \\
\hline \multicolumn{4}{|l|}{ sampint 1} \\
\hline \multicolumn{4}{|l|}{ Senjolit } \\
\hline \multicolumn{4}{|l|}{ Semples } \\
\hline \multicolumn{4}{|l|}{ Saterpitet } \\
\hline \multicolumn{4}{|l|}{ semples } \\
\hline 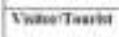 & & & \\
\hline Orerat apsizo & & & \\
\hline
\end{tabular}

Colombo Street

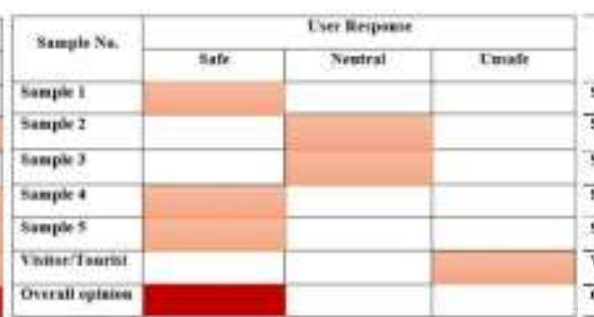

Cross Street

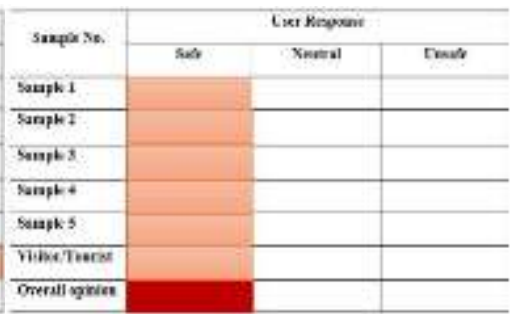

Dalada Veediya 
Fig. 3: User response in three case streets Source: Author

2. Analyzed responses of selected users for the questionnaires and semi-structured interviews as follow,

I. Dalanda Street is perceived by many visitors and shop owners as safest street which is taken into the study as a pedestrian space with positive physical attributes.

II. Colombo Street and Prince Street are perceived by many samples and shop owners as unsafe street which has negative physical attributes.

III. Kotugodalla Street is accepted by pedestrians as safe but deviate with the ideas of shop owners and the $\mathbf{2 0 1 5}$ police crime map shows many burglary and theft cases along this street.

IV. Wadugodapitiya Street is perceived as unsafe by the pedestrians but shop owners admit it as safe because the police station is pretty close to the street. There were no crime incidents happened within this street.

v. User responses on Yatinuwara Street, D S Senanayake Street, Hill Street, Cross Street and King Streets relatively these streets considered as according to answers of pedestrians.

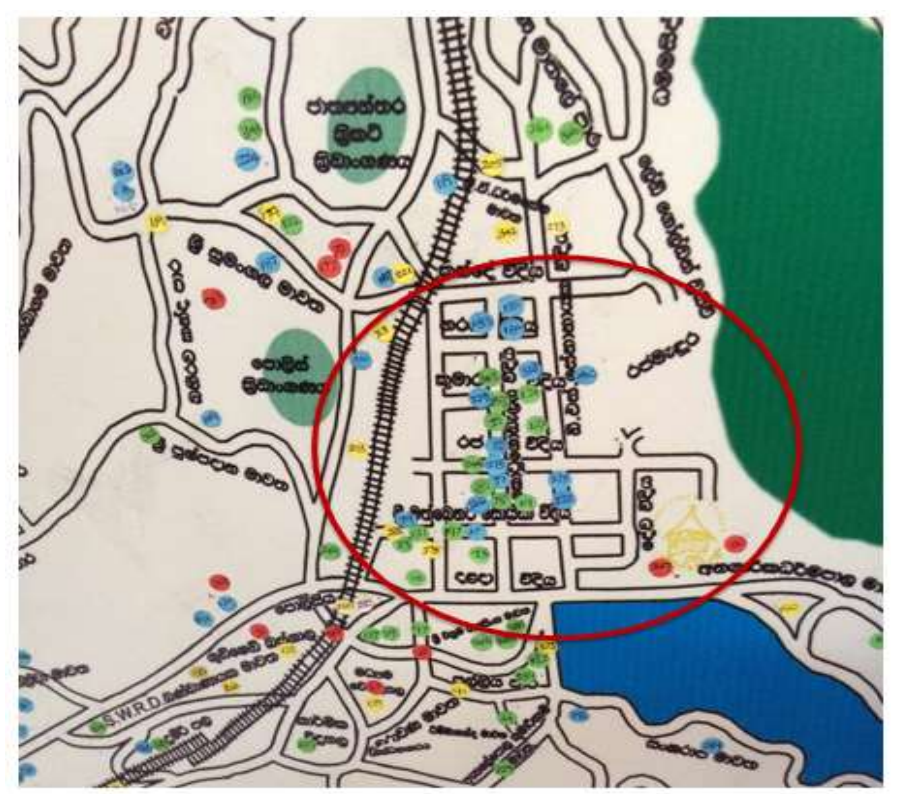

dull. Yet can be safe streets the

Key
Burglary cases
Property stealing (Above 25,000 LKR)
Robbery cases
Violent cases


Fig. 4: Crime map of Kandy grid city -2015

Source: Crime division, Kandy police station

3. Space Data Analysis Results

I. Space data were analyzed using colored maps which are highlighting the unsafe spots and zones and further analysis were done using the photographs taken.

II. Summary data of overall physical attributes of pedestrian spaces which extracted by walking observations and photographic surveys

III. High color tones represent the positive attributes and low color tones represent the negative physical attributes in final summery chart.

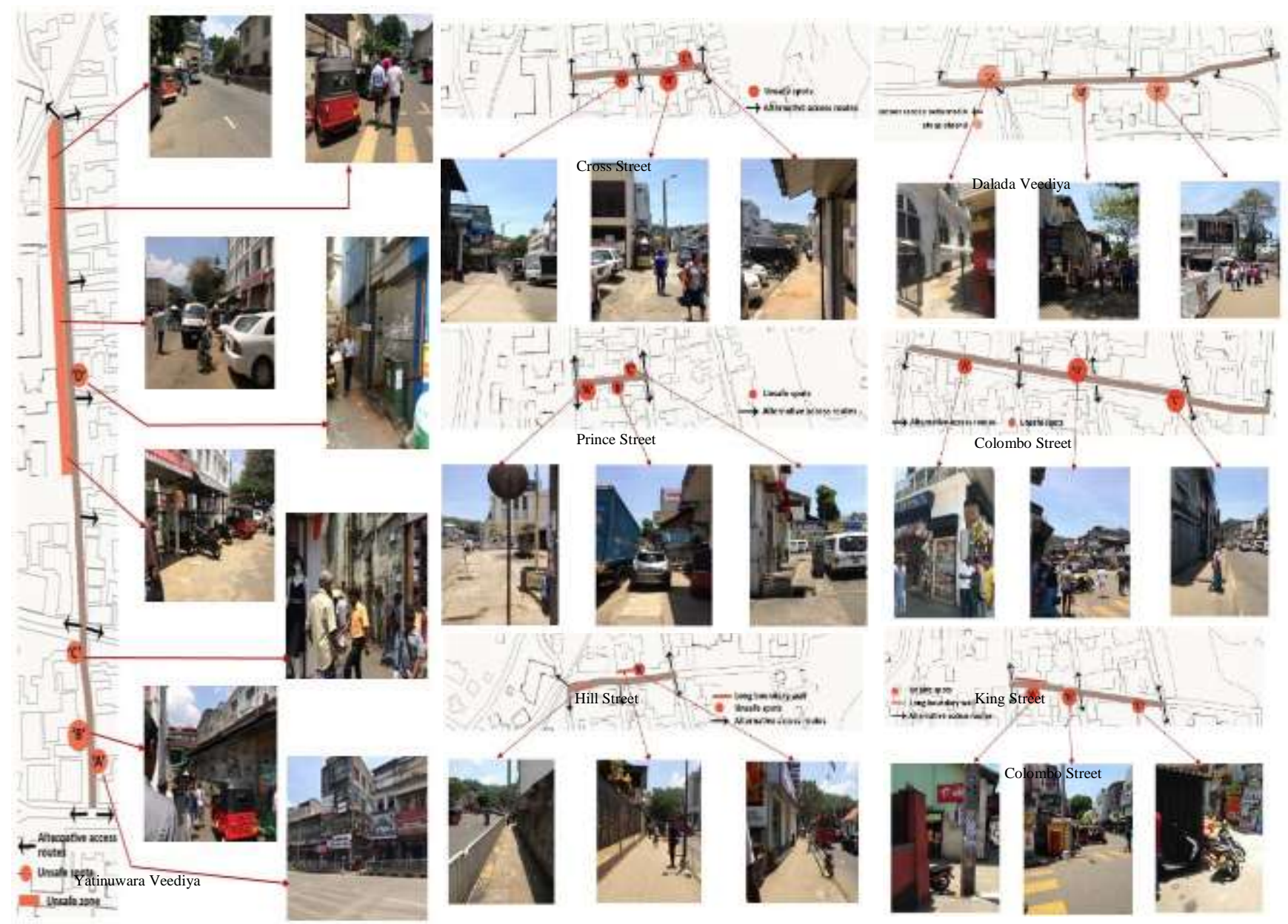


Fig. 5: Space data findings of each street Source: Author

(Rational - If a street contains more than $50 \%$ of blocks exceeding the $20 \mathrm{~m}$ length, it considers as a street with long block lengths.

If a street contains more than $50 \%$ of blocks exceeding two stories or higher, it considers as a street with tall blocks.

Solid-void ratios - if 1:1(approximately), consider as more void

If $>1: 1$ consider as more solid

\begin{tabular}{|c|c|c|c|}
\hline Physical Attributes & Positive & Comments \& Colour Codes & Negative \\
\hline Block Length & Short & Long & \\
\hline Block height & Tall & Short & \\
\hline Façade Colours & Contrast & Dull & \\
\hline Façade Textures & Textured & Plain & \\
\hline Solid - Void Ratio & More Void & More Solid & \\
\hline Sidewalk Condition & Safe & Unsafe & \\
\hline Accessibility & High & Low & \\
\hline Rhythm \& Pattern & Yes & No & \\
\hline Repitition & Yes & No & \\
\hline Natural \& Artificial Lighting & Sufficient & Insufficient & \\
\hline Shadings & $\overline{\text { Sufficient }}$ & Insufficient & \\
\hline Visibiility/Surveillance & High & Low & \\
\hline Historic presence & More than $25 \%$ & Less than $25 \%$ & \\
\hline Formal / Informal Activities & Mix primary use & Only commercial & \\
\hline Special Functions & Yes & No & \\
\hline
\end{tabular}

Fig. 6: Key for the color codes of Summary chart of the Analysis Source: Author

\begin{tabular}{|c|c|c|c|c|c|c|c|c|c|c|c|c|c|}
\hline \multirow{2}{*}{\multicolumn{2}{|c|}{$\begin{array}{l}\text { Key Physical } \\
\text { Attribute }\end{array}$}} & \multicolumn{2}{|r|}{ Data Variable } & \multicolumn{10}{|c|}{ Overall Comment for Places } \\
\hline & & No. & Design Featurn & $\begin{array}{l}\text { Daluda } \\
\text { Veodya }\end{array}$ & $\begin{array}{l}\text { Colambo } \\
\text { street }\end{array}$ & $\begin{array}{l}\text { Nings } \\
\text { Street }\end{array}$ & $\begin{array}{l}\text { Namara } \\
\text { Veediya }\end{array}$ & $\begin{array}{l}\text { Cross } \\
\text { street }\end{array}$ & Hill street & $\begin{array}{c}\text { Wadrgodapitha } \\
\text { Veedivi: }\end{array}$ & $\begin{array}{c}\text { Vatinuwara } \\
\text { Veedya }\end{array}$ & $\begin{array}{l}\text { Cotugodela } \\
\text { Veediye }\end{array}$ & $\begin{array}{c}\text { DS. } \\
\text { Senanavake } \\
\text { Yecolval }\end{array}$ \\
\hline \multirow{5}{*}{01} & \multirow{5}{*}{$\begin{array}{l}\text { Bult form Aelated } \\
\text { Hwikal } \\
\text { Atributes }\end{array}$} & 1 & Black Leneth & & & & & & & & & & \\
\hline & & 2 & Block heityt & & & & & & & & & & \\
\hline & & 3 & Fapade Colourn & & & & & & & & & & \\
\hline & & 4 & Façade Tentures & & & & & & & & & & \\
\hline & & 5 & Sold-Void Ratio & & & & & & & & & & \\
\hline \multirow{4}{*}{02} & \multirow{4}{*}{$\begin{array}{l}\text { Flanning \& Layout } \\
\text { related Physical } \\
\text { Antributes }\end{array}$} & E & Sidtewalk Conditien & & & & & & & & & & \\
\hline & & 7 & Accesubitity & & & & & & & & & & \\
\hline & & B & Bhythm \& Pattern & & & & & & & & & & \\
\hline & & 9 & Flephition & & & & & & & & & & \\
\hline \multirow{4}{*}{ as } & \multirow{4}{*}{$\begin{array}{l}\text { Ambience Reinted } \\
\text { Awsical } \\
\text { Attributes }\end{array}$} & 10 & $\begin{array}{l}\text { Natura } 8 \text { Artifoal } \\
\text { Lighting }\end{array}$ & & & & & & & & & & \\
\hline & & 11 & Shadines & & & & & & & & & & \\
\hline & & 12 & Vistality/ Surveltance & & & & & & & & & & \\
\hline & & 13 & Hieturk bresence & & & & & & & & & & \\
\hline \multirow{2}{*}{04} & \multirow{2}{*}{$\begin{array}{l}\text { Functional } \\
\text { Related Plysical } \\
\text { Attributes }\end{array}$} & 14 & $\begin{array}{l}\text { Formal / informal } \\
\text { Activeres }\end{array}$ & & & & & & & & & & \\
\hline & & 15 & Soecial Functions & & & & & & & & & & \\
\hline
\end{tabular}


Fig. 7: Summery chart of physical attributes of each street Source: Author

\section{Discussion}

In order to conclude the findings of the research conducted, the main objective is to investigate the relationship between perception of safety and physical attributes of pedestrian spaces and identify the legitimate physical attribute combinations to ensure the safety within pedestrian spaces. Accordingly, the two main variables have been tested against perceived safety and physical attributes of pedestrian spaces with reference to the Kandy city.

Respectively, fifteen attributes are identified and analyzed within the research area, which categorized under four key physical attributes considering built form, planning and layout, ambience and functions.

Analyzed space data is indicated in a summery chart to come up with an evidence based conclusion on the physical attributes that facilitates the perception of safety. Following conclusion has been made by observing the summery chart.

- Perception of safety of a pedestrian is not just depending on the physical safety of the pedestrian space or the sidewalk. It is affected by other physical attributes as well. That is because the pedestrians have perceived some streets as safe even its sidewalk condition is not good enough or well-maintained and uncomfortable which reflects unsafety.

- At least there should be positive physical attributes from all four key categories which are built form, planning and layout, ambience and functions. Because the streets which are perceived as unsafe by pedestrians missing physical attributes from one or few categories.

- At least there should be a combination of any ten positive physical attributes as representing key categories to ensure the perception of safety. That is because the positive application of built form related attributes basically provide attraction, planning and layout related attributes provide comfort and both ambience and functional related physical attributes provide confidence which are essential factors in ensuring the safety. Therefore, representing key attributes is a must.

- Hence a historic city has been selected as case of this research, it can be clearly identified that the historic presence is vital to ensure the safety which causes to generate (a) rhythm (b) pattern and (c) repetition. Besides contrast/vibrant colors and textures of facades are totally effective in ensuring the perception of safety in pedestrian spaces. That is why, almost all perceived safe streets are positive application of façade colors, textures, rhythm, pattern and repetition with a high historic building percentage.

- Besides positive application of solid-void ratio and diversity of functions are essential in facilitating the safety. 
- Some streets are accepted by pedestrians as safe but not the shop owners. The reason is, these streets contain essential positive physical attributes to accept it as safe by pedestrians. But lack of lighting and visibility make it victimize to the thefts and burglaries.

Besides long block lengths and improper building setbacks create many unsafe spaces along those streets. According to the previous crime experience, shop owners do not accept the street as safe. (Maruthaveeran \& van den Bosch, 2014) It elaborates that the previous crime experience (direct or indirect victimization) and prior information about crime, impact on perceived safety.

- Some of the streets do not contain essential positive physical attributes. Therefore, pedestrians perceived that particular street as not safe. But, the mix of uses and activities/spaces which are located close to police station, sense the street safe and protected from crimes resulting shop owners perceived it as safe.

Considering the above findings, it is clear that there is a direct and strong relationship between perception of safety and the physical attributes of pedestrian spaces. Also, there should be minimum fulfilments of set of positive attributes in order to ensure the safety within pedestrian spaces. These attributes have been differed with the city character, its history, culture and magnitude of functionality. But, at least, there should be a combination of some particular positive attributes to facilitate the perception of safety in a highly functional and historic city such as Kandy.

\section{References:}

Alexander, C. (1968). Discouraging crime through city planning. Oakland, California: Harvard university press.

Bently, I. (1985). Responsive environments: a manual for designers. London: Architectural press.

(2010). Better street plans: policies and guidelines for the pedestrian realm. San Francisco: San Francisco planning department.

DiLeo, A., Thacher, J., \& Rampson, W. (2011). Downtown Ann Arbor design guidelines. Ann Arbor: Downtown Ann Arbor city council.

Gehl, J. (2010). Cities for people. Washington DC: Island press.

Greenbie, B. B. (1981). Spaces: dimensions of the human landscape. Yale university press: London.

Henriksen, J. (1996). An investigation of rhytm and repetition in architectural theory and precedent. Rome.

Jacobs, A. B. (1995). Great streets. Cambridge, MA: MIT press.

Jacobs, J. (1961). The death and life of great American cities. New York: Random House U.S.A. Karunanada, S. T. (2015). Experiencing sense of safety in urban neighborhood streets: study on fear of crime in Kotahena. University of Moratuwa.

Krier, R. (1979). Urban space. London: Acadamy editions.

Lars Gemzoe, Jahn Ghel. (2008). Public space for public life. Seattle: GHEL architects Aps.

Lynch, K. (1960). The image of the city. Massachusetts: MIT press.

Maruthaveeran, S., \& van den Bosch, C. K. (2014). A socio-ecological exploration of fear of crime in urban green spaces: A systematic review. Elsevier, 1-18.

Mehta, V. (2013). The street: a quintessential social public space. New York: Routledge.

Mumford, L. (1964). The highway and the city. London: Secker \& Warbug.

Newman, O. (1972). Defensible space: people and design in the violent city. New York: Macmillan company.

Patel, S. (1998). Making cities safe for women and children. Mumbai: SPARC. 
Rathnayake, R. (2013). Fear of crime in the built environment. Colombo: University of Moratuwa Sandamali, K. T. (2014). Study of The attributes of people oriented streets towards transforming urban setting into walkable cities. Colombo: University of Moratuwa.

Spooner, D. D. (2007). Enclosure and walkability: an Italian street study. University of Georgia press.

Tuan, Y.-F. (1977). Space and place: The perspective of experience. Minneapolis: University of Minnesota press.

Acknowledgments:

This research work was supported by the Accelerating Higher Education Expansion and Development (Ahead) project of the Ministry of Higher Education of the Sri Lankan Government and the World Bank. 